\title{
Onda ou Partícula? Um Estudo das Trajetórias Ontológicas da Radiação Eletromagnética em Livros Didáticos de Física da Educação Básica
}

\section{Wave or Particle? A Study of Ontological Trajectories of Eletromagnetic Radiation in Physics High School Textbooks}

\author{
Pedro Antônio Viana Vazata ${ }^{\circledR}$ Brasil \\ Nathan Willig Lima ${ }^{\circledR}$ Brasil \\ Fernanda Ostermann ${ }^{\circledR}$ Brasil \\ Cláudio José de Holanda Cavalcanti ${ }^{\circledR}$ Brasil
}

Neste artigo, partimos de elementos da Sociologia da Ciência de Bruno Latour para analisar atores da Educação em Ciências. De acordo com Latour, a Educação em Ciências participa da rede da Ciência no elo da representação pública. Deste modo, professores, livros didáticos, dentre outros membros desta rede (humanos e não-humanos), podem ser compreendidos como parte da própria Ciência, sendo que a Educação em Ciências e as Ciências participam da rede uma da outra. A partir desta perspectiva, catalogamos enunciados retirados de três livros didáticos aprovados no edital do PNLDEM 2018 de acordo com a tipologia proposta por Latour para analisar enunciados de cientistas. Em uma primeira análise qualitativa, buscamos compreender a trajetória ontológica de diferentes interpretações para a radiação eletromagnética no contexto da Física clássica e moderna. Ademais, valemo-nos de uma segunda arguição qualitativa do dictum e do modus destes enunciados, para elucidar os recursos estilísticos utilizados pelos autores de livros didáticos na construção das trajetórias ontológicas de actantes. Nossos resultados demonstraram que, nos três livros analisados, somente a luz tida como onda no contexto clássico atinge a autonomização. Apesar disso, enunciados com alto grau de realidade foram encontrados para interpretações ontológicas antagônicas.

Palavras-chave: livro didático; Estudos das Ciências; CTS; Latour; Física Moderna; Física Quântica.

In this paper, we start from elements of the Sociology of Science by Bruno Latour to analyse actors in Science Education. According to Latour, Science Education participates in the Science network in the public representation link. In this way, teachers, textbooks, among others members of this network (human and non-human), can be understood as part of Science itself, with Science Education and the Sciences participating in each other's network. From this perspective, we catalog statements taken from three textbooks 
approved in the PNLDEM 2018 edict according to the typology proposed by Latour to analyse statements by scientists. In a first qualitative analysis, we seek to understand the ontological trajectory of diferente interpretations for eletromagnetic radiation in the context of classical and modern physics. In addition, we make use of a second qualitative argument of the dictum and the modus of these statements, to elucidate the stylistic resources used by the authors of textbooks in the construction of the ontological trajectories of actants. Our results showed that, in the three analysed books, only the light seen as a wave in the classical context reaches autonomy. Despite this, statements with a high degree of reality were found for antagonistic ontological interpretations.

Keywords: Textbook; Science Studies; STS; Latour, Modern Physics; Quantum Physics.

\section{Introdução}

Neste trabalho, partimos da concepção de Ciência como cultura, ou seja, partimos do pressuposto de que essa não pode ser entendida apartada de suas bases materiais, dos instrumentos e dos símbolos que são compartilhados e negociados em seu contexto de realização (Geertz, 1973), e, de uma forma geral, de toda a rede sociociotécnica (composta por humanos e não-humanos) que mobilizam tal atividade (Latour, 1994). Em especial, neste trabalho, reconhecemos que um elemento constitutivo essencial da rede científica é a linguagem praticada pelos cientistas e materializada em cartas, artigos, e livros (Lightman, 2016). Nesse sentido, entender a Ciência passa, também, por entender suas manifestações linguísticas e discursivas.

Ressaltamos que o privilégio da linguagem como objeto de pesquisa entrou nos Estudos das Ciências ${ }^{1}$ por diferentes caminhos. Em especial, na segunda onda CTS, conhecida como a Antropologia do Laboratório (Collins \& Evans, 2002), Latour e Woolgar (1986) conectam a estrutura fraseológica utilizada para se falar de determinado fato com o "grau de realidade" atribuído a ele, e os teóricos da Teoria Ator-Rede valemse da terminologia da linguística de Greimmas e Courtés (1982) para analisar as Ciências (Callon, 1984; Latour, 1993, 2005; Law, 1984). De acordo com esta perspectiva, ademais, a ciência não pode ser pensada como uma entidade isolada, autoexistente, que se autoalimenta e regula a si mesma. Pelo contrário, Bruno Latour (1999) defende e sustenta que a Ciência funciona como um sistema circulatório, estendendo-se pelos diferentes espaços da sociedade.

A partir dessa perspectiva, alguns autores defendem a possibilidade de ressignificação da área de Educação em Ciências não como um campo isolado ou até mesmo subserviente à rede da Ciência, mas como um elemento constitutivo da própria rede científica (Weinstein, 2008) ou para ser mais preciso, a Ciência e a Educação em Ciência podem ser entendidas como sistemas complexos que se encontram e se conectam de forma interdependente (Lima et al., 2019). Não faz sentido falar de Educação em

1 Estudos das Ciências é um termo genérico utilizado para designar as pesquisas sobre as Ciências, usualmente sob um viés sociológico (Latour, 1999). 
Ciências sem pensar na rede das Ciências, mas tão pouco faz sentido analisar a Ciência sem pensar, também, na rede da Educação em Ciências.

O caso mais exemplar de tal conexão se dá no processo de formação de cientistas. Em geral, atualmente, não há cientistas que não tenham passado por uma educação formal - o que tem sido objeto de análise sob o nome de pedagogia científica (Kaiser, 2005, 2006). Ademais, um elemento material emblemático da cultura da pedagogia científica, no âmbito da formação dos cientistas, é o que conhecemos, hoje, como "livro didático" (Lightman, 2016).

A importância do livro didático não somente para a educação, mas para a própria prática científica foi claramente destacada por Thomas Kuhn (1996) em sua discussão sobre manuais de instrução e, desde então, muitos estudos têm tratado do papel dos livros didáticos para a história da Ciência (Badino \& Navarro, 2013; Kaiser, 2005). No caso da Educação Básica, a relação entre a rede da Ciência e da Educação em Ciência também não pode ser subestimada. Conforme discutimos na seção 2, a Educação em Ciências desempenha um papel crucial para a rede da Ciência, ao atuar diretamente na construção da opinião pública sobre a prática científica e sobre o papel da Ciência na sociedade. Nesse contexto, novamente, o livro didático aparece como um elemento material e cultural essencial, desempenhando um papel importante no processo pedagógico (Lima et al., 2018).

Assim, neste trabalho, partimos de três reconhecimentos: 1) a Ciência é uma prática cultural; 2) a Educação em Ciências e as Ciências são redes que se relacionam e; 3) o livro didático é um elemento material importante nessas redes. Partindo dessa concepção, podemos afirmar que livros didáticos usados na Educação em Ciências participam do processo descrito por Bruno Latour (Latour, 1999) como "estabilização ontológica", isto é, a trajetória pela qual passa um determinado actante ${ }^{2}$ para deixar de ser considerado uma hipótese para ser considerado um elemento da realidade. Esse processo foi descrito por Latour e Woolgar (1986) e, posteriormente, por Latour (1999) no âmbito dos laboratórios. Usando a concepção de sistema circulatório da Ciência, entretanto, podemos estender sua ocorrência em todo o sistema científico, incluindo a rede da Educação em Ciências.

Conforme apontam Latour e Woolgar (1986), o processo de translação de um actante do mundo das ideias para o mundo real é mediado pela linguagem, através de diferentes combinações de "dictum" e "modus" e, de fato, pode ser mensurado por meio de uma análise linguística. A partir de tal concepção, nosso objetivo é estender a proposta de Latour (1999), analisando a trajetória ontológica de actantes não no contexto do Laboratório, mas no contexto da rede da Educação em Ciências, evidenciando que há um processo dinâmico e "quente" quando os livros didáticos tratam de alguns actantes. Mais especificamente, nosso objetivo é avaliar a trajetória ontológica da natureza da radiação eletromagnética em livros didáticos de Física aprovados no Plano Nacional do Livro Didático de 2018. Esse actante é de especial interesse, pois é apresentado e discutido em

2 O termo actante é definido na seção 2. 
dois contextos diferentes nos livros didáticos: na Física Clássica, no qual é concebido como uma onda eletromagnética, e na Física Moderna, na qual é descrito através do fóton, um ente quântico que, apesar de indivisível, sofre interferência - manifestando, portanto, uma natureza dual (cujas características não podem ser satisfatoriamente tratadas por teorias clássicas).

Através de uma combinação de dois processos de análise qualitativa de enunciados, pretendemos responder às seguintes perguntas: quais os diferentes níveis ontológicos assumidos pela onda eletromagnética no contexto clássico e qual trajetória ontológica é apresentada para esse actante? A luz como onda eletromagnética é totalmente estabilizada ontologicamente? Quais os diferentes níveis ontológicos assumidos pelo fóton no contexto moderno e qual trajetória ontológica é apresentada para esse actante? A luz como fóton é totalmente estabilizada ontologicamente? A trajetória ontológica apresentada em ambos contextos é capaz de formar uma narrativa ontologicamente consistente na obra como um todo? Quais as consequências pedagógicas das trajetórias ontológicas apresentadas pelos livros?

Ressaltamos, ademais, que esse trabalho, por abordar um tema de Física Quântica em livros didáticos de ensino médio, dialoga com diferentes pesquisas que se preocupam, de uma forma mais ampla, com o tema do livro didático (Cassab \& Martins, 2008; Justi \& Gilbert, 2000; I. Martins, 2006), com a presença da Física Moderna nos livros didáticos da Educação Básica (Contents et al., 2019; Marques et al., 2019; Zang et al., 2019), e, mais especificamente, com o papel da linguagem e do discurso nos enunciados de Física Moderna nos livros da Educação Básica (Kopp \& Almeida, 2019; Lima et al., 2017; Lima et al., 2018b).

\section{Estudos sociológicos das Ciências}

Bruno Latour é um dos precursores de estudos sobre a prática científica sob a ótica da Antropologia do Laboratório (Latour, 1994; Latour \& Woolgar, 1986). No entanto, iniciou sua vida acadêmica no campo da antropologia, se dedicando a realizar estudos etnográficos em tribos "não-modernas". Posteriormente voltou seu olhar ao centro da sociedade para estudar a Ciência em ação, algo inovador não somente no campo da antropologia como no da epistemologia (Lima et al., 2018a). Seus primeiros estudos relacionados à prática científica foram descritos em sua obra $A$ vida de Laboratório (Latour \& Woolgar, 1986). Neste livro, os autores fazem um minucioso relato sobre o ofício dos cientistas em um laboratório de Neuroendocrinologia no instituto Salk, na Califórnia (EUA). Latour acompanhou, por dois anos, o dia a dia do laboratório e descreveu o funcionamento dessa "tribo" de cientistas. Após este primeiro trabalho no campo epistêmico, Latour publicou diversas obras em que busca retratar não somente o funcionamento da práxis científica como a produção do conhecimento científico, contribuindo para o aprofundamento do debate ontológico a partir de sua visão simétrica entre natureza e sociedade.

Estendendo a linha filosófica não-essencialista de Sartre (2007), para Latour a 
natureza não é composta por uma realidade pré-determinada, à espera do ser humano para ser descoberta (Latour, 1994; Lima et al., 2018a). Sob essa ótica, o que define e caracteriza a existência de um actante ${ }^{3}$ são as articulações entre teorias, equipamentos, experimentos, equações, cientistas, políticos e os demais membros que compõe sua rede. As articulações entre os actantes da rede definem o quão "real" eles são; quanto mais actantes compõem essa rede e mais articulações são feitas entre eles, mais "real" é o actante. Caso, em um dado momento, as teorias percam sua validade, os políticos cortem investimentos, os equipamentos parem de funcionar, e demais articulações sejam desfeitas, a rede como um todo irá enfraquecer juntamente à existência desse actante (Lima et al., 2019). Sendo assim, a realidade de um actante não é uma propriedade binária e varia ao longo do tempo, podendo ser estabilizada (maior articulação da rede), ou desestabilizada (maior desarticulação da rede).

\section{Estudos sociológicos na Educação em Ciências}

Os estudos de Latour se direcionam, a princípio, a investigar a prática científica, não estando presentes em suas obras aspectos conectados diretamente à Educação em Ciências. No entanto, Latour evidencia a necessidade de a Ciência transpor os muros acadêmicos para que permaneça em pleno desenvolvimento. Nesse sentido faz-se necessário que diversos setores da sociedade façam parte da rede da Ciência.

Em sua obra $A$ esperança de Pandora (Latour, 1999), o autor relata a história de Frédéric Joliot e sua tentativa de realizar a primeira reação nuclear artificial em 1939. Segundo Latour não se pode contar esta história por duas vertentes, uma interna (científica) e outra externa (político-social). Nesta formulação haveria dois tipos de historiadores, um para explicar a parte política e social, em que seria constada a história de políticos, empresários, economistas e industriais e outra para explicar as teorias científicas, contanto a história dos cientistas. Os estudos científicos simétricos têm o objetivo de romper com essa divisão, contando uma única história. Joliot necessita desenvolver uma maneira de desacelerar os nêutrons das primeiras fissões para que aconteça a reação em cadeia, mas também necessita convencer políticos franceses de que esse é o caminho mais eficiente para alcançar a independência nacional. No sentido inverso da história, um político que estava compenetrado em arrumar soluções para vencer os nazistas, agora necessita compreender o processo de funcionamento da fissão nuclear e decidir se investirá tempo e dinheiro em um projeto audacioso que pode ser utilizado como artifício de guerra.

A fim de explicar as relações entre os aspectos naturais e sociais, Latour utiliza a comparação do processo de produção científica com o sistema circulatório sanguíneo (Latour, 1999). Segundo o autor existem cinco atividades em que os cientistas necessitam estar envolvidos para o pleno funcionamento da prática científica a fim de mobilizar

3 Latour faz uso do termo actante (retirado da semiótica), a fim de incluir em seu discurso os "atores nãohumanos", visto que a palavra ator se remete somente aos humanos. A teoria da relatividade, as Leis de Newton e Albert Einstein são exemplos de actantes (Latour, 1999). 
instrumentos, colegas, aliados e o público. Cada uma dessas atividades representa um dos elos da figura 1. O primeiro elo, a mobilização do mundo, remete à prática de laboratório e ao levantamento de dados. O segundo elo, a autonomização, se refere à busca por colegas e instituições a fim de expandir a rede de pesquisa. $\mathrm{O}$ terceiro elo, as alianças, retratam a necessidade de estabelecer contatos com instituições, políticos e outros setores da sociedade para o financiamento de pesquisas. O quarto elo, a representação pública, retrata a necessidade do conhecimento científico se fazer presente perante a sociedade. O quinto e último, os nós, são a conexão entre todos os elos. Se algum destes elos for suprimido ou enfraquecido, comprometerá o sistema circulatório da Ciência como um todo.



Figura 1. O sistema circulatório da Ciência (Adaptado de Latour, 1999)

Defendemos em trabalhos anteriores (Lima et al., 2019) que a Educação em Ciências participa do elo da representação pública - influenciando a concepção das pessoas sobre as Ciências e sobre o papel das Ciências na sociedade. A opinião pública, por sua vez, afeta a capacidade de formação de alianças, e essa, por sua vez, viabiliza ou impede a mobilização do mundo e, por consequência, a autonomização. O papel da educação científica, portanto, é um processo fundamental para a existência da Ciência, é afetado por ela e a afeta. Neste contexto, o livro didático de Ciências, da educação básica, deve ser entendido como parte constitutiva da rede da Ciência, pois através dele os conhecimentos científicos e a própria noção do que é Ciência é difundida na sociedade. Desta maneira, os métodos desenvolvidos por Latour para analisar artigos científicos e falas do laboratório, podem ser estendidos para investigar os discursos no contexto científico-didático. Mais especificamente, nesse artigo, estamos interessados em entender como que a construção das trajetórias ontológicas de actantes científicos é mediada pelos livros didáticos. 


\section{Estabilização ontológica de actantes}

Como discutido no início desta seção, Latour aponta que os cientistas constroem híbridos; tentando, no entanto, eliminar de sua produção a esfera social e discursiva. Tal movimento cria os fatos científicos, em que todo o processo de construção da Ciência é apagado. Segundo o autor, a eliminação destes aspectos não é feita de maneira abrupta pelos cientistas e sim de forma gradual, através da transformação de seu discurso ao longo da construção de suas teorias. Em sua obra Jamais fomos modernos, o autor discute como a essência do vácuo foi construída ao longo da história através de diferentes concepções. Ao mencionar quais dessas concepções de fato representam a essência do vácuo o autor indaga "O que é o vácuo então? Nenhuma dessas posições. A essência do vácuo é a trajetória que liga todas elas." (Latour, 1994, p. 85). A construção discursiva dessa trajetória é exemplificada por Latour no trecho a seguir:

Considere esta frase: (1) "Cada nêutron libera 2,5 nêutrons". Isto é o que se lê hoje em enciclopédias. Isso é o que é chamado de "fato científico". Agora vamos analisar outra frase: (2) "Joliot afirma que cada nêutron libera de 3 a 4 nêutrons, mas isso é impossível; ele não tem provas; é otimista demais (...)" Diferentemente da sentença (1), a sentença (2) não está de acordo com as regras estilísticas que governam o aparecimento dos fatos científicos: ela não pode ser lida em nenhuma enciclopédia. Seu caráter datado é facilmente discernível. Podemos notar que essas duas frases têm uma seção em comum, a declaração ou dictum*: "cada nêutron libera x nêutrons" e uma parte muito diferente, composta de um conjunto de situações, pessoas e julgamentos, chamado de modificador ou modus*. (Latour, 1999, p. 93, tradução nossa)

Segundo Latour e Woolgar (1986), enquanto a rede de um dado actante for pequena, os escritores necessitam transmitir credibilidade aos demais cientistas, portanto, em seu discurso serão feitas menções à rede que o articula, como por exemplo, o nome de cientistas envolvidos, o laboratório em que são feitos os testes, datas, dentre outras informações do gênero. Além disso, se adotarão recursos estilísticos de escrita que transmitam caráter conjectural e especulativo. No entanto, conforme a rede se expande, e a credibilidade do actante aumenta, o escritor começa a suprimir as menções a sua rede e tornará a escrita objetiva, transmitindo ao leitor a noção de descoberta do fato científico, como se esse sempre tivesse existido. Este processo é denominado por Latour de estabilização ontológica. Apesar de tentar apagar a construção do conhecimento científico, o processo de estabilização deixa rastros no discurso dos cientistas.

Em A vida de Laboratório, Latour e Woolgar (1986) caracterizam o discurso dos cientistas em cinco diferentes tipos de enunciados. A fim de promover a estabilização ontológica de um actante, os cientistas transformam enunciados do tipo 1 (conjecturas) em enunciados do tipo 5 (fato tido como adquirido); os tipos de enunciados estão resumidos na Figura 2. Latour e Woolgar (1986) indicam que nos manuais (livros didáticos), estão presentes, em sua maioria, enunciados do tipo 4 (saber aceito). 


\begin{tabular}{|l|l|l|}
\hline Tipos de Enunciados & Exemplos \\
\hline Tipo 1 & Conjecturas & $\begin{array}{l}\text { Vamos supor que a radiação seja composta } \\
\text { por um conjunto de elementos discretos. }\end{array}$ \\
\hline Tipo 2 & $\begin{array}{l}\text { Modalidades que insistem na generalidade } \\
\text { dos dados }\end{array}$ & $\begin{array}{l}\text { Podem-se interpretar alguns dados com a } \\
\text { quantização da radiação. }\end{array}$ \\
\hline Tipo 3 & Modalidades: Enunciados sobre Enunciados & $\begin{array}{l}\text { Einstein afirmou que a radiação é } \\
\text { quantizada. }\end{array}$ \\
\hline Tipo 4 & Saber Aceito & A radiação é quantizada. \\
\hline Tipo 5 & $\begin{array}{l}\text { Fato tido como adquirido (não precisam ser } \\
\text { expressos, raramente aparecem) }\end{array}$ & Os fótons foram absorvidos pelo gás. \\
\hline
\end{tabular}

Figura 2. Tipos de Enunciados encontrados em um laboratório (Lima et al., 2018a)

Como estamos interessados em discutir o processo de estabilização da natureza da radiação eletromagnética nos livros didáticos, apresentamos uma breve história do processo de articulação e estabilização desse actante pela comunidade científica. Ressaltamos que estamos sintetizando cem anos de história em uma página e, certamente, isso não pode ser feito sem grandes perdas. Tentamos, entretanto, apenas ressaltar alguns aspectos da história que são apontados pela literatura especializada como importantes e que terão papel central na análise dos livros didáticos. Para uma discussão aprofundada dessa história remetemos o leitor aos livros historiográficos e de fundamentos de Física Quântica (Greenstein \& Zajone, 2006; Kuhn, 1978; Martins \& Rosa, 2014).

\section{Diferentes visões sobre a Natureza da Radiação Eletromagnética}

No contexto da Física Clássica, todos os entes físicos poderiam ser divididos em um esquema ontológico com dois grandes grupos: corpos materiais (com localização bem definida no espaço, com massa, e tendo seu movimento descrito pelas Leis de Newton) e campos contínuos, como o campo eletromagnético (distribuídos de forma contínua pelo espaço, imponderáveis, e sendo responsáveis por mediar as interações entre os corpos materiais). Dentro desse esquema teórico, a natureza ondulatória da luz foi estabelecida, primeiramente, através da mobilização de uma rede sociotécnica, que viabilizou a interpretação de experimentos de interferência da luz - um fenômeno tipicamente ondulatório. Dentro do quadro teórico Latouriano, pode-se dizer que os experimentos de interferência e a teoria ondulatória foram mobilizados para articular a natureza ondulatória da luz. Tal articulação, ademais, foi intensamente reforçada com a entrada de um novo actante (as equações de Maxwell do Eletromagnetismo). Com o desenvolvimento da Teoria Eletromagnética, não só foi possível se conceber que a luz é uma onda; mas, também, que ela possui uma natureza eletromagnética, ou seja, a luz (dentro dessa construção teórica) é uma onda eletromagnética que se propaga pelo espaço sem a necessidade de nenhum meio material. É possível, nesse sentido, imaginar que, até o início do século XX, a natureza ondulatória da luz estava ontologicamente estabilizada. 
Diferentes estudos, entretanto, no início do século XX passaram a sugerir que, talvez, a luz devesse ser tratada como uma partícula — desarticulando a proposição inicial. O primeiro a sugerir isso (nesse contexto) foi Albert Einstein em 1905 (Einstein, 1905) propondo que a radiação eletromagnética, dentro dos limites de validade do modelo de Wien, deveria ser entendida de forma semelhante a um gás diluído. Essa proposta foi elaborada por diversos outros cientistas que, então, propuseram a possibilidade de fótons (a partícula de radiação eletromagnética) colidirem como se fossem partículas (Compton, 1923) ou até mesmo que fótons poderiam ter massa (de Broglie, 1922).

Deve-se ressaltar, entretanto, que essas propostas para a natureza da luz são corpusculares no sentido clássico. Isto é, entendem que, no esquema ontológico da Física Clássica, a luz deveria ficar no grupo dos corpos (partículas). A partir de 1909, entretanto, não só a natureza ondulatória da luz passou a ser desarticulada, mas o próprio esquema ontológico da física clássica. Einstein (1909) propôs que os quanta (conjunto de quantum ou fóton) deveriam ser acompanhados por um campo vetorial contínuo, sugerindo a primeira noção dual para a luz (Martins \& Rosa, 2014). Isso, entretanto, não foi muito aceito ou difundido pela comunidade científica.

Um ponto crucial, entretanto, na história da luz se deu 81 anos depois da proposta corpuscular clássica inicial de Einstein (1905), quando Aspect e colaboradores (Grangier et al., 1986) fazem o primeiro experimento monofotônico, indicando, ao mesmo tempo, a existência de fótons únicos e a possibilidade de um fóton interferir (Greenstein \& Zajone, 2006). Ou seja, a partir de 1986 tem-se evidência de que, sim, a luz é quantizada (o que poderia ser associada com uma característica corpuscular); mas esse fóton "interfere consigo mesmo" (Dirac, 1958) (o que poderia ser associado com uma característica ondulatória). Nesse sentido, nem uma visão corpuscular clássica, nem uma visão ondulatória dão conta do comportamento do fóton. A Mecânica Quântica, assim, desarticula não só a natureza ondulatória da luz, mas desestabiliza a própria ontologia clássica.

Atualmente, podemos descrever a quantização do campo eletromagnético matematicamente no contexto da Teoria Quântica de Campos ou da Óptica Quântica, mas a interpretação dos resultados experimentais ou mesmo a interpretação do formalismo matemático não é consensual e depende da interpretação da teoria a ser adotada, da mesma forma que a interpretação da função de onda varia dentro da Física Quântica não-relativística (Jammer, 1974).

Nesse sentido, de forma sintética, podemos dizer que a luz (ou radiação eletromagnética de uma forma mais geral) é entendida na Física Clássica (Teoria Eletromagnética):

Interpretação Ondulatória Clássica: a luz é uma onda eletromagnética. Ela se distribui de forma contínua pelo espaço. Não há um limite inferior de energia para uma determinada onda eletromagnética.

Interpretação Corpuscular semi-clássica: no início do século $\mathrm{XX}$, foi desenvolvida uma visão corpuscular da luz muito semelhante à uma visão corpuscular 
clássica (pois não reconhecia fenômenos ondulatórios para um fóton único), como no caso de Einstein (1905), de Broglie (de Broglie, 1922) e Compton (Compton, 1923). A luz é composta por fótons, porções indivisíveis de radiação eletromagnética. Efeitos ondulatórios só são possíveis em um conjunto de fótons. Nesse caso, algumas propriedades físicas dos fótons são caracterizadas por parâmetros ondulatórios (como na equação que relaciona energia e frequência).

Com a consolidação da Física Quântica (FQ), diferentes interpretações foram desenvolvidas para dar conta do comportamento dual da luz. A discussão detalhada das diferentes interpretações da FQ e, também, da natureza da luz foge ao escopo deste trabalho, de forma que utilizaremos a classificação proposta por (Pessoa Jr., 2003) para o fóton em termos de quatro grupos de interpretação:

(i) Interpretações Corpusculares: o fóton é uma partícula. Os fenômenos de interferência em experimentos monofotônicos podem indicar a necessidade de redefinir conceitos lógicos em nível quântico, o que é conhecido como Lógica Quântica, ou mesmo formar a noção de propensidade como uma propriedade física (Popper, 2002) e desenvolver uma interpretação estatística (Ballentine, 1970)

(ii) Interpretações Ondulatórias: a luz é, de fato, uma onda. O aspecto quantizado da luz, entretanto, pode ser explicado através de noção de colapso da função da onda. Ou seja, diante de uma medida, a onda seria colapsada em apenas um possível autoestado (um possível resultado da medida). Essa visão era defendida por Schrödinger (1928) e muitas interpretações hidrodinâmicas (Jammer, 1974)

(iii) Interpretações dualistas realistas: a luz é composta por um elemento corpuscular e por uma onda que guia essa partícula. Essa onda (indetectável) é responsável por "guiar" a partícula. Visão desenvolvida, por exemplo, por de Broglie (1924)

(iv) Interpretações dualistas positivistas: o que determina a natureza ondulatória ou corpuscular é o tipo de experimento realizado. Um experimento corpuscular (que envolve a determinação de trajetória, por exemplo) revela um aspecto corpuscular, e um experimento ondulatório (que provoca interferência) revela um aspecto ondulatório. Nesse sentido, não faz sentido perguntar o que a luz "é", mas o que cada experimento pode revelar. Essa visão foi defendia com o desenvolvimento da Complementaridade por Niels Bohr (1928)

Ressaltamos que existe uma grande variedade de interpretações da Física Quântica. A presente classificação reúne diferentes interpretações por uma de suas características mais marcantes, a dizer, o posicionamento ontológico sobre a natureza ondulatória ou corpuscular da luz (ou da função de onda, no caso não-relativístico). Poderia se agrupar as interpretações usando outros critérios, como o conceito de probabilidade a que 
aderem, por exemplo. Para presente pesquisa, entretanto, consideramos que o presente esquema de classificação é suficiente para avaliar o problema proposto.

Por fim, explicitamos que se pode fazer um paralelo entre o que estamos realizando e o que Latour faz ao analisar a estabilização dos micróbios de Pasteur, em detrimento da fermentação química (Latour, 1999). Em ambos casos, há dois actantes tentando ser articulados e tentando desarticular o outro actante. A diferença é que nós estamos avaliando como essa "competição" ontológica se transfere para o contexto científicopedagógico - contexto não analisado por Latour.

\section{Metodologia}

A estrutura metodológica deste trabalho foi baseada em trabalhos anteriores, nos quais analisamos a trajetória ontológica de actantes em livros didáticos de Ciência (Vazata et al., 2018, 2019). Elaboramos este dispositivo analítico a partir da categorização proposta por Latour em seu livro A vida de Laboratório, descrita na seção anterior. Com base neste dispositivo, sistematizamos nossa pesquisa conforme a sequência de passos descrita abaixo.

\section{Primeira etapa}

\section{Escolha do actante a ser analisado}

Dentre os tópicos de Física discutidos na educação básica, escolhemos analisar o actante Radiação Eletromagnética, tendo em vista que não há consenso na comunidade científica em relação a sua natureza ontológica. Segundo Montenegro e Pessoa Jr. (2002) existem ao menos quatro grupos de interpretações acerca da natureza da luz: ondulatória (realista), corpuscular (realista), dualista (realista) e dualista positivista.

\section{Escolha dos livros aprovados no edital do PNLDEM 2018 a serem analisados}

Em relação a escolha dos livros a serem analisados, baseamo-nos no trabalho de Lima et al. (2018b). Segundo os autores, os 14 livros didáticos de Física aprovados no edital do PNLDEM 2015 se dividem em três categorias em relação à maneira como apresentam as interpretações da radiação eletromagnética. A primeira categoria representa 11 livros, que não reconhecem explicitamente as diferentes interpretações e não aderem especificamente a nenhuma delas. Na segunda categoria estão 2 livros que reconhecem explicitamente a diferença entre as interpretações. A terceira categoria representa o único livro que adere a somente uma interpretação, defendendo-a como a única possibilidade. Escolhemos para análise, portanto, um livro de cada uma destas categorias, descritos abaixo:

Primeira categoria: volume 3 do livro didático de Bonjorno et al. (2016) intitulado Física: eletromagnetismo, física moderna. O livro de Bonjorno, segundo dados do FNDE (2017), foi o livro com maior distribuição nas escolas da rede pública brasileira referente ao edital PNLDEM 2015 (os dados do último edital não foram divulgados até então). 
Analisamos a unidade 3, da página 184 até 195 e a unidade 4 página 225 até 237.

Segunda categoria: volume 3 do livro didático de Pietrocola, Pogibin, Andrade, e Romero (2016) intitulado Física em contextos. Analisamos as unidades 3 e 4, da página 124 até 207.

Terceira categoria: volume 3 do livro didático de Gaspar (2016) intitulado Compreendendo a Física: eletromagnetismo e física moderna. Analisamos o capítulo 11, da página 187 até 203.

\section{Escolha dos termos para seleção dos enunciados}

A seleção dos enunciados, foi realizada a partir da escolha de termos previamente identificados que faziam menção de alguma forma à natureza ontológica da radiação eletromagnética, são eles: onda, ondulatória, corpúsculo, corpuscular, partícula, quanta, quantum, "pacote de energia" e fóton.

\section{Segunda etapa (primeira análise qualitativa)}

\section{Seleção dos enunciados que fazem referência ao actante escolhido}

A partir da escolha dos termos, realizamos uma leitura minuciosa dos capítulos do livro que remetiam à explicação da natureza ontológica da luz a partir do contexto clássico (eletromagnetismo) e moderno (Física Quântica). Todos os enunciados que continham os termos identificados foram tabelados na ordem em que apareciam no texto. Para cada livro elaboramos duas tabelas, uma para luz como onda e outra para luz como partícula, nos contextos clássico e moderno.

\section{Classificação dos enunciados de acordo com a tipologia de Latour}

A cada enunciado foi atribuído um número correspondente a um dos 5 tipos de enunciados proposto por Latour e Woolgar (1986) ${ }^{4}$.

\section{Análise tipológica da trajetória ontológica do actante}

Elaboramos dois gráficos (contexto clássico e moderno) e a partir deles analisamos a trajetória ontológica da luz em cada um dos contextos, constatando sua possível estabilização.

\section{Terceira etapa (segunda análise qualitativa)}

\section{Separação do dictum e do modus}

Selecionamos alguns enunciados de cada livro e separamos o dictum (aquilo que permanece inalterado na frase) do modus (a parte da frase que é suprimida ou alterada).

4 Ver Figura 2. 


\section{Análise qualitativa do dictum e do modus}

Fizemos uma análise fraseológica, identificando quatro aspectos dos enunciados:

a) Existência, ou não, de detalhes da rede: nome do cientista, localização e data.

b) Natureza dos verbos utilizados. Exemplo: "Einstein descobriu o fóton." ou "Einstein supôs que a luz fosse composta por partículas, denominadas fóton.".

c) Estrutura do enunciado. Exemplo: "A luz possui um caráter dual, às vezes se comporta como onda às vezes como partícula." ou "Pode-se entender que a luz possui um caráter dual, às vezes se comporta como onda às vezes como partícula.".

d) Identificação de agente humano "Maxwell comprovou a existência de ondas eletromagnéticas..." ou não-humano "A teoria desenvolvida por Maxwell comprovou a existência de ondas eletromagnéticas...".

\section{Análise de dados}

Assim como a metodologia foi dividida em duas etapas qualitativas, os resultados, também, serão apresentados em duas seções, correspondendo aos momentos da pesquisa. Na primeira análise qualitativa, discutimos a trajetória ontológica da natureza ondulatória e corpuscular da luz tanto no contexto clássico quanto moderno/quântico. Após essa análise, alguns enunciados foram selecionados para serem minuciosamente explorados em relação à sua estrutura fraseológica, segundo os passos 7 e 8 do nosso método de análise, o que é mostrado na seção da segunda análise qualitativa.

\section{Análise tipológica dos enunciados na trajetória ontológica da natureza ondulatória e corpuscular da luz}

A partir dos resultados obtidos, elaboramos dois gráficos para cada um dos livros; um gráfico traduz a trajetória ontológica para a natureza ondulatória da luz, e outro traduz a trajetória ontológica para a natureza corpuscular da luz. Ambos os gráficos possuem os enunciados nos contextos clássico, ou seja, no âmbito do eletromagnetismo (em azul) e no âmbito do desenvolvimento da $\mathrm{FQ}$, a qual foi subdivida em um período "moderno" (vermelho) e "dual"(verde) para diferenciar quando, explicitamente, aparece a natureza dual da radiação, que é uma característica central da teoria quântica (Feynman et al., 2013).

Os gráficos mostram no eixo vertical as cinco categorias de estabilização ontológica (Figura 2) e ao longo do eixo $\mathrm{x}$ a ordem do enunciado analisado (ao longo do texto) - assim o número 1 é o primeiro enunciado extraído do livro, o número 2 é o segundo e assim por diante. Assim, o gráfico mostra a evolução da trajetória ontológica do actante em questão (luz ondulatória e luz corpuscular) ao longo do texto. 


\section{i) Física: eletromagnetismo, física moderna (Bonjorno et al., 2016)}

Este livro foi analisado em um trabalho anterior de (Vazata et al., 2019). A Figura 3 contêm os enunciados referentes à natureza ondulatória da luz, tanto no contexto clássico como no moderno. Pode-se perceber que, no contexto clássico, a natureza ondulatória passou por um processo de estabilização ontológica. Nas primeiras páginas do livro, que remetem à explicação da luz sob a ótica ondulatória, os autores traçam uma linha histórica acerca da evolução da teoria, evidenciando datas, locais e cientistas que colaboraram para o seu desenvolvimento, além disso, os verbos utilizados transparecem um caráter conjectural. No entanto, finalizada a breve contextualização histórica, as menções à rede, presentes sob a forma de enunciados do tipo 3, não são mais encontradas, aparecendo somente enunciados dos tipos 4 (Saber aceito) e 5 (Fato tido como adquirido). Segundo a visão latouriana, os autores deste livro didático ao desenvolverem o conceito de luz no contexto clássico, seguem o mesmo estilo discursivo dos cientistas, apagando a rede sociotécnica. A radiação eletromagnética como onda no contexto clássico torna-se, portanto, algo natural como se sempre tivesse existido. Nesta formatação, o livro dá preferência para a apresentação do conceito físico ao invés de explicitar sua construção. Ao fazer isso, o actante luz ondulatória passa a ser um fato, um objeto do mundo real, e não do mundo das ideias. Não se pensa a luz como onda, a luz é uma onda.

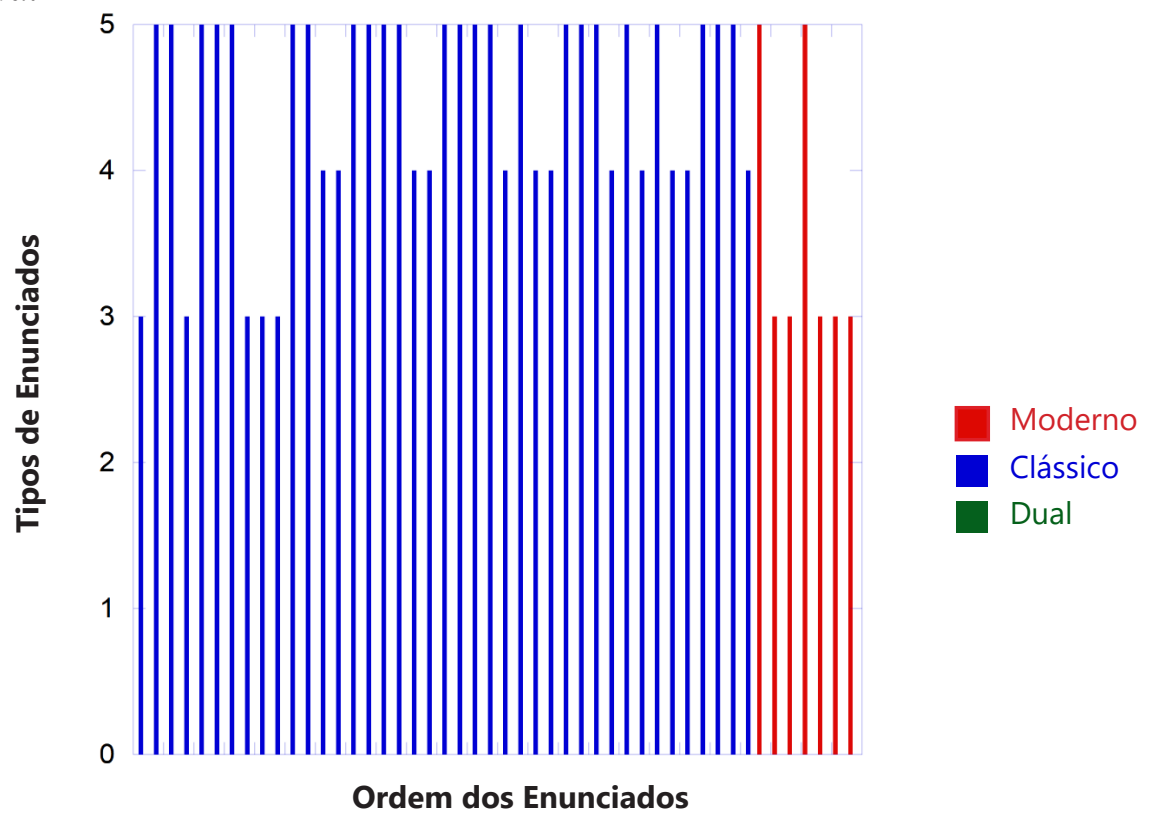

Figura 3. Trajetória ontológica da luz como onda nos contextos clássico e moderno no livro de Bonjorno et al., (2016). No eixo x estão os enunciados, na ordem que aparecem no livro. No eixo y os 5 tipos de enunciados segundo a tipologia de Latour. Adaptado de Vazata et al., (2019)

No contexto moderno a radiação eletromagnética ondulatória passa por uma desarticulação, seguindo um padrão diferente dos enunciados dos cientistas no laboratório. A abundância de enunciados tipo 4 e 5 é substituída pela alternância entre enunciados tipo 5 e 3, sendo que é finalizado com enunciados tipo 3. Comparando as 
Figuras 3 e 4, percebe-se que no contexto moderno há uma quantidade muito maior de enunciados corpusculares do que ondulatórios, ou seja, a visão ondulatória clássica é desestabilizada em detrimento da visão corpuscular. Chamamos atenção, também, que a visão ondulatória não aparece em nenhuma discussão dual, ou seja, a visão ondulatória fica circunscrita à visão clássica.

A Figura 4 apresenta os dados referentes à luz sob a perspectiva corpuscular. A primeira diferença evidente para visão ondulatória é o fato de o texto não possuir nenhum enunciado no contexto clássico, somente moderno, como seria esperado. As primeiras 9 frases, que apresentam o fóton, se fazem presentes num capítulo de física clássica, num "box", para explicar o funcionamento do laser. Então, embora a natureza corpuscular da luz apareça na discussão da física clássica, ela é feita em uma caixa apartada do texto principal, apenas apontando para o que será discutido posteriormente. Os enunciados subsequentes se fazem presentes somente nos capítulos de Física Moderna. Desta vez os autores trazem o debate para o nível conjectural e histórico, em que são encontrados diversos enunciados do tipo 3 até o final do livro. No meio da apresentação, inclusive, é colocado um enunciado tipo 2. Nesse sentido, podemos afirmar que a luz corpuscular não atinge a estabilização ontológica, entendendo-se, portanto, que as diferentes interpretações, no contexto moderno, são somente possíveis interpretações; mas não a realidade. Assim, se por um lado a luz ondulatória é estável no contexto clássico, nenhuma das duas é estável no contexto moderno/quântico. Ressaltamos, ademais, que a natureza corpuscular não aparece também em nenhum enunciado dual. Ou seja, o texto não chega a tratar propriamente de Física Quântica, como já havíamos apontado em trabalho anterior (Lima et al., 2018).



Figura 4. Trajetória ontológica da luz como partícula nos contextos clássico e moderno no livro de Bonjorno et al., (2016). No eixo x estão os enunciados, na ordem que aparecem no livro. No eixo y os 5 tipos de enunciados segundo a tipologia de Latour. Adaptado de Vazata et al., (2019) 
Conclusões sobre o livro:

1) O livro aborda diferentes intepretações para a natureza ontológica da radiação eletromagnética.

2) O livro fomenta a estabilização ontológica da luz somente para a interpretação ondulatória no contexto clássico.

3) Apesar de somente uma das interpretações atingir a autonomização, estão presentes no livro enunciados do tipo 5 (alto grau de realidade) para a natureza corpuscular e ondulatória.

\section{ii) Física em contextos 3 (Pietrocola et al., 2016)}

O livro é dividido em 3 unidades, sendo que as duas últimas são dedicadas à explicação da radiação eletromagnética. A unidade 2 é intitulada Ondas Eletromagnéticas e a unidade 3 Radiação e matéria.

Os autores indicam no início da unidade 2 que esta será exclusivamente dedicada à natureza ondulatória da luz e que as demais interpretações (retomando também a visão ondulatória, no entanto ressaltando aspectos históricos) será discutida somente na próxima unidade. Os autores já partem de imediato à explicação conceitual do fenômeno físico, portanto identificamos somente um enunciado do tipo 2 e três enunciados do tipo 3 nesta unidade, sendo que enunciados do tipo 5 são os mais frequentes (as últimas 19 frases da unidade são do tipo 5). A luz ondulatória no contexto clássico torna-se um fato científico, no terço final da unidade 2 , a partir da $32^{\mathrm{a}}$ frase todas são dos tipos 4 ou 5. Uma das frases desta unidade retrata o alto grau de realidade atribuído pelos autores à natureza ondulatória da luz, "Este padrão de interferência construtiva (regiões claras) e destrutiva (regiões escuras) foi o que comprovou definitivamente a natureza ondulatória da luz." (Pietrocola et al., 2016, p. 138). No entanto, como veremos a seguir, essa frase que denota realidade à visão ondulatória na unidade 2 , é desarticulada na unidade 3.

O primeiro capítulo da unidade 3 é intitulado A natureza da luz e, logo na primeira seção deste capítulo, discutem-se as controvérsias a respeito da natureza da luz ao longo da história. $\mathrm{O}$ alto grau de realidade articulado pelos autores para radiação eletromagnética sob aótica ondulatória na unidade 2 se perde e enunciados do tipo 1 são os mais encontrados ao longo desta unidade. Neste capítulo, dá-se preferência à abordagem histórica ${ }^{5}$ acerca da natureza da luz, remontando ao debate entre Newton (defendendo a visão corpuscular) e Huygens (defendendo a visão ondulatória ${ }^{6}$ ) no século XVII e

\footnotetext{
5 Segundo Latour, esta abordagem histórica se encaixaria na história interna da Ciência, ou seja, a história dos cientistas, pois questões sociais e políticas não são abordadas no texto.

6 Os autores do livro deixam subentendido ao longo do texto que a visão de Huygens era ondulatória, mas não a associam diretamente, conforme fica evidente neste trecho do texto ao mencionar o conceito do cientista "O segundo, por sua vez, acreditava que se tratava de uma perturbação que ocorria em uma suposta matéria sutil, que ele, assim como vários filósofos gregos da Antiguidade, chamava de éter." (Pietrocola et al., 2016).
} 
posteriormente do debate entre Fresnel (ondulatória) e Poisson (corpuscular) no século XIX. Após duas seções sobre a relatividade geral e restrita, os autores retomam a discussão sobre as diferentes interpretações da radiação eletromagnética abordando concepções modernas acerca de sua ontologia. Nota-se que nesta unidade a postura epistemológica dos autores muda drasticamente, como é evidenciado em uma frase do capítulo 1 desta unidade "Em Ciência, nada é definitivo. Sua história mostra como certezas categóricas se tornam insuficientes com o desenvolvimento contínuo de pesquisas." (Pietrocola et al., 2016, p. 181). Esta postura é refletida na abordagem discursiva utilizada para elucidar o desenvolvimento das teorias. Portanto, nesta unidade, a visão ondulatória é desarticulada.

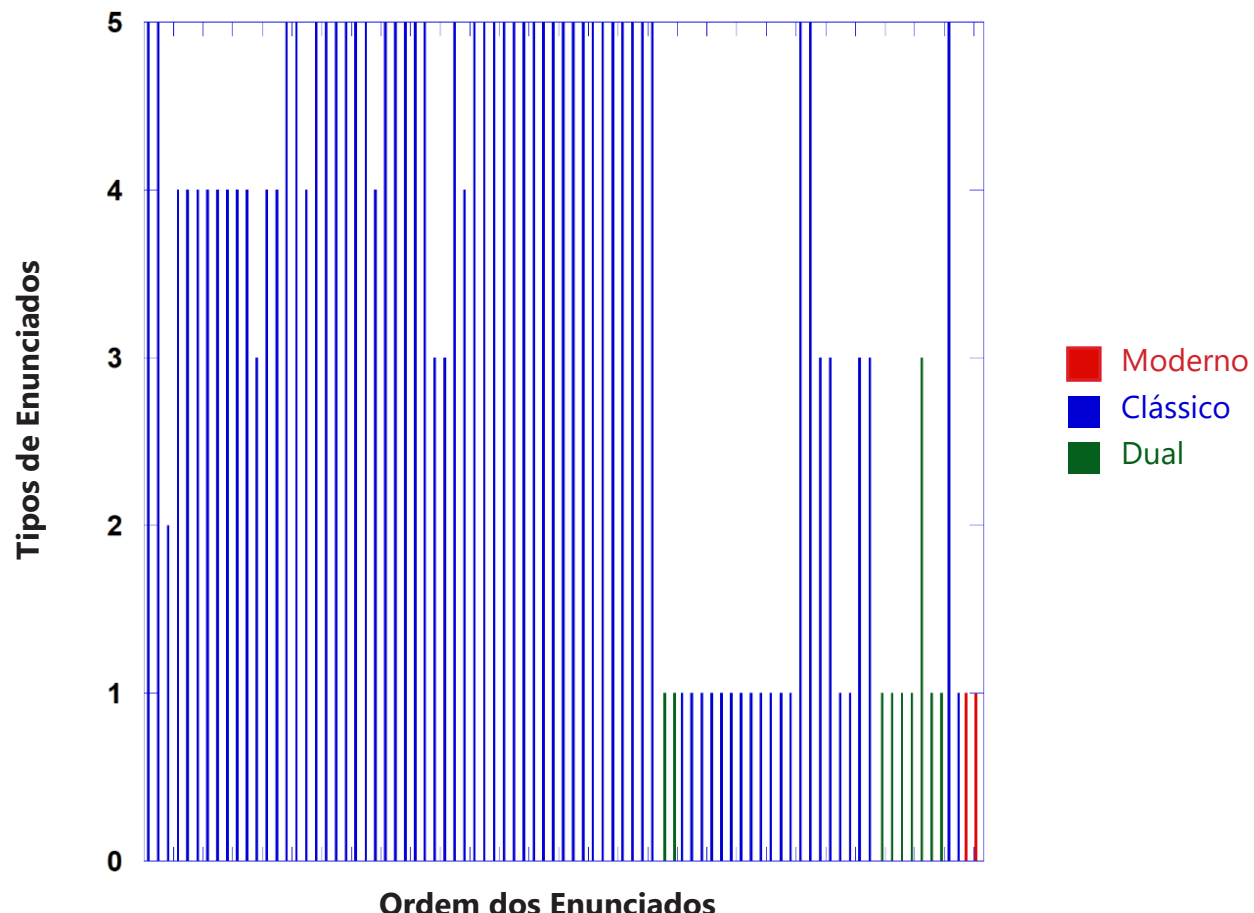

Figura 5. Trajetória ontológica da luz como onda nos contextos clássico e moderno no livro de Pietrocola et al., (2016). No eixo x estão os enunciados, na ordem que aparecem no livro. No eixo y os 5 tipos de enunciados segundo a tipologia de Latour

A unidade 3 é dedicada à discussão de diferentes interpretações sobre a natureza da luz. Além disso, nesta unidade outras teorias da Física Moderna são abordadas além da radiação eletromagnética. Os autores, como mencionado anteriormente, iniciam a unidade trazendo uma ampla contextualização histórica sobre a natureza ontológica da luz. A última seção do capítulo 8 é intitulada $O$ que é a luz, afinal?. Nesta seção os autores fazem um resumo de toda a discussão, desde os tempos de Newton até a atualidade, sintetizando em quatro interpretações possíveis para a natureza da radiação eletromagnética: ondulatória, corpuscular, dualista realista e complementariedade (dualista positivista).

A Figura 6 evidencia que a radiação eletromagnética sob a ótica corpuscular não atinge em nenhum contexto (clássico ou moderno) estabilização ontológica. As seções 
do capítulo 8 que discutem explicitamente a natureza da luz são em geral dedicadas à abordagem histórica e de caráter conjectural. Os autores só utilizam enunciados do tipo 5 quando necessitam explicar fenômenos físicos, como o efeito fotoelétrico, que são melhores compreendidos sob a ótica corpuscular, explicitado no seguinte trecho do texto, "Quanto maior a intensidade da luz incidente, mais fótons atingem a superfície do metal, fazendo um número maior de elétrons ser emitido." (Pietrocola et al., 2016, p. 204).



Figura 6. Trajetória ontológica da luz como partícula nos contextos clássico e moderno no livro de Pietrocola et al., (2016). No eixo x estão os enunciados, na ordem que aparecem no livro. No eixo y os 5 tipos de enunciados segundo a tipologia de Latour

Conclusões sobre o livro:

1) O livro aborda diferentes interpretações a respeito da natureza ontológica da radiação eletromagnética.

2) A interpretação ondulatória no contexto clássico na unidade 2 passa pelo processo de estabilização ontológica. Na unidade 3 esta visão é desarticulada.

3) Mesmo que os autores indiquem que existem ao menos quatro interpretações acerca da natureza da luz, sua abordagem discursiva e a estrutura das unidades e capítulos (dedicando uma unidade inteira à interpretação ondulatória, enquanto que a interpretação corpuscular não possui sequer um capítulo exclusivo) podem transparecer ao leitor que a intepretação ondulatória possui um grau de realidade maior que as demais interpretações. 
4) Apesar de somente uma das interpretações atingir a autonomização, estão presentes no livro enunciados do tipo 5 (alto grau de realidade) para a natureza corpuscular e ondulatória.

5) As unidades 2 e 3 devem ser analisadas independentemente, pois a visão ondulatória dentro do contexto clássico possui alto grau de realidade na unidade 2 e baixo grau de realidade na unidade 3. Além disso, as posturas epistemológicas das duas unidades são antagônicas, na unidade 2 a Ciência é tida como fonte da verdade, na unidade 3 os autores abordam a Ciência como uma construção humana.

iii) Compreendendo a Física: eletromagnetismo e física moderna (Gaspar, 2016)

A discussão sobre a natureza ontológica da luz se dá somente no capítulo 11 (Das ondas eletromagnéticas aos fótons) da unidade 3 do livro. $\mathrm{O}$ autor defende explicitamente a visão corpuscular como sendo a única possível e atribuindo a interpretação ondulatória caráter meramente instrumental, como observado neste trecho do livro "Embora haja evidências incontestáveis da natureza corpuscular da luz, há também fenômenos luminosos que só se explicam adequadamente com a teoria ondulatória." (Gaspar, 2016, p. 197). Sua abordagem discursiva como um todo não reflete a posição defendida nesta frase, pois ao longo do texto a radiação eletromagnética sob a ótica ondulatória, no contexto clássico, passa pelo processo de estabilização ontológica, como é possível observar na Figura 7. Já no contexto moderno a visão da luz ondulatória não é estabilizada.

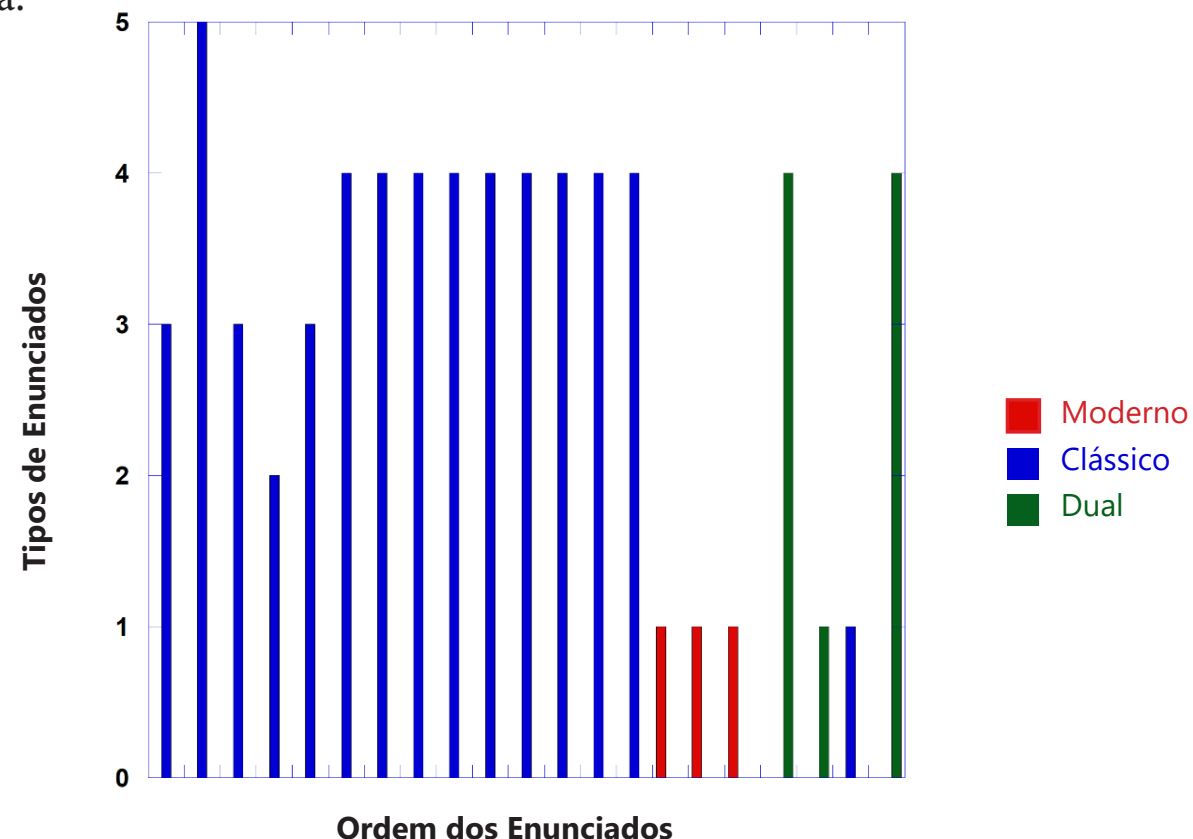

Figura 7. Trajetória ontológica da luz como onda nos contextos clássico e moderno no livro de Gaspar, (2016). No eixo x estão os enunciados, na ordem que aparecem no livro. No eixo y os 5 tipos de enunciados segundo a tipologia de Latour 
A defesa explícita da natureza corpuscular da luz não se reflete na estabilização ontológica dessa. Ao longo do texto em nenhum contexto a visão corpuscular é autonomizada, como vemos no gráfico da Figura 8. Ao longo de todo o texto se encontram enunciados do tipo 2 e 3 , mesmo que em dado momento os enunciados do tipo 4 e 5 sejam os mais encontrados.

Apesar de apresentar diferentes interpretações para a natureza ontológica da radiação eletromagnética, esse é o único livro presente no edital do PNLDEM 2018 que confere a somente uma interpretação o status de verdadeira, ou seja, segundo os autores somente a visão corpuscular corresponde a uma realidade no mundo, sendo adotada, portanto, uma postura epistemológica realista. As demais interpretações seriam, segundo o autor, capazes de resolverem problemas, sem corresponderem a uma realidade no mundo, adotando uma postura epistemológica instrumentalista. Entretanto, como destacamos anteriormente, o autor não sustenta sua proposição denotando baixo grau de facticidade à luz sob a ótica corpuscular.



Figura 8. Trajetória ontológica da luz como partícula nos contextos clássico e moderno no livro de Gaspar, (2016). No eixo x estão os enunciados, na ordem que aparecem no livro. No eixo y os 5 tipos de enunciados segundo a tipologia de Latour

Conclusões sobre o livro:

1) O livro aborda diferentes interpretações a respeito da natureza ontológica da radiação eletromagnética.

2) Somente uma das interpretações (corpuscular) é considerada possível explicitamente, as demais são apresentadas de modo instrumentalista. 
3) Apesar de apresentar diferentes interpretações e destacar que somente a corpuscular é real, o livro fomenta a estabilização ontológica da luz somente para a interpretação ondulatória no contexto clássico.

4) Dos três livros analisados, este é o que dedica menos páginas para a discussão sobre a natureza da luz, além disso, é o único que possui mais frases para explicar a natureza corpuscular que a ondulatória. Estes dados podem ter correlação com a crença do autor de que existe somente uma interpretação possível para explicar a radiação eletromagnética e que ela é corpuscular.

A Figura 9 apresenta um resumo da análise apresentada. No quadro é possível identificar a presença, ou não, de três elementos nos livros: presença da interpretação, se possui enunciados do tipo 4 ou 5 no texto e por fim se a interpretação foi estabilizada.

\begin{tabular}{|c|c|c|c|c|c|}
\hline \multicolumn{3}{|c|}{ Livros } & \multirow{2}{*}{$\begin{array}{l}\text { Física: } \\
\text { eletromagnetismo } \\
\text { e física moderna } \\
\mathrm{x}\end{array}$} & \multirow{2}{*}{$\begin{array}{c}\text { Física em } \\
\text { contextos } \\
\mathrm{x} \\
\end{array}$} & \multirow{2}{*}{\begin{tabular}{l} 
Compreendendo \\
a física: \\
eletromagnetismo e \\
física moderna \\
\multicolumn{1}{c}{$\mathrm{x}$} \\
\end{tabular}} \\
\hline \multirow{12}{*}{ 异 } & \multirow{3}{*}{$\begin{array}{l}\text { Ondulatória } \\
\text { (clássico ou } \\
\text { moderno) }\end{array}$} & Presente & & & \\
\hline & & Autonomização $^{7}$ & $\mathrm{x}$ & $\mathrm{x}$ & $\mathrm{x}$ \\
\hline & & Tipo 4 ou 5 & $\mathrm{x}$ & $\mathrm{x}$ & $\mathrm{x}$ \\
\hline & \multirow{3}{*}{$\begin{array}{l}\text { Corpuscular } \\
\text { (clássico ou } \\
\text { moderno) }\end{array}$} & Presente & $\mathrm{X}$ & $\mathrm{x}$ & $\mathrm{x}$ \\
\hline & & Autonomização & & & \\
\hline & & Tipo 4 ou 5 & $\mathrm{X}$ & $\mathrm{x}$ & $\mathrm{x}$ \\
\hline & \multirow{3}{*}{$\begin{array}{l}\text { Dualista } \\
\text { (realista) }\end{array}$} & Presente & & $\mathrm{x}$ & \\
\hline & & Autonomização & & & \\
\hline & & Tipo 4 ou 5 & & & \\
\hline & \multirow{3}{*}{$\begin{array}{l}\text { Dualista } \\
\text { (positivista) }\end{array}$} & Presente & $\mathrm{x}^{8}$ & $\mathrm{x}$ & $\mathrm{x}^{9}$ \\
\hline & & Autonomização & & & \\
\hline & & Tipo 4 ou 5 & & & \\
\hline
\end{tabular}

Figura 9. Resumo das interpretações para a radiação eletromagnética apresentadas nos livros

7 A autonomização ocorre somente no contexto clássico nos três casos.

8 Não apresenta enunciados para dualidade em nossos gráficos, ao apresentar esta interpretação os autores não utilizam nenhuma das palavras escolhidas como parâmetro de seleção das frases.

9 A visão dualista presente no livro não corresponde nem a visão dualista realista nem a dualista positivista. A interpretação apresentada pelo autor fica evidente no seguinte trecho "Para a Física atual, não há dúvida de que um feixe de luz é um feixe de partículas, isto é, um feixe de fótons. A dualidade surge em relação ao comportamento coletivo desse feixe, que é ondulatório." (Gaspar, 2016, p. 197). Esta abordagem reforça a crença do autor na natureza corpuscular da luz. 


\section{Análise das formas de modalização de enunciados usados nos processos de construção das trajetórias ontológicas da luz como onda ou como partícula}

Como discutido anteriormente, segundo Latour os enunciados possuem o dictum (o que permanece) e o modus (o que é modificado/subtraído). De acordo com a tipologia do autor, frases do tipo 1 ao 3 possuem os dois, já nos enunciados do tipo 4 e 5 encontra-se apenas o dictum, devido ao seu alto grau de realidade. Ainda, segundo o autor, nos manuais didáticos predominariam enunciados do tipo 4 (saber aceito), o que não corresponde com os livros analisados, em que foram encontradas diversas frases dos cinco tipos de enunciados. Percebe-se, portanto, que os manuais analisados não se valem de recursos discursivos semelhantes aos utilizados em laboratórios para descrever a trajetória ontológica da radiação eletromagnética. A fim de elucidar a trajetória ontológica de actantes, será demonstrado a seguir a análise do modus de dois enunciados dos tipos 1, 2 e 3.

Enunciado tipo 1: "O processo mais simples que pode ser imaginado é aquele em que um quantum de luz transfere toda a sua energia a um único elétron." (Gaspar, 2016, p. 193).

Dictum: Um quanta de luz transfere toda sua energia a um único elétron.

Análise do modus: Neste enunciado o autor se refere a uma possível interpretação do fenômeno. Ao utilizar o verbo imaginar, pode-se entender que esta interpretação não reflete algo do mundo físico. Todo o modus diminui a realidade do actante.

Enunciado tipo 1: "Finalmente, o efeito fotoelétrico voltava a sugerir que a luz e todas as ondas eletromagnéticas se comportavam como pacotes de energia, ou seja, como partículas bem delimitadas se propagando no espaço." (Pietrocola et al., 2016, p. 206)

Dictum: A luz é composta por pacotes de energia.

Análise do modus: O trecho "voltava a sugerir" indica que esta é apenas uma possibilidade de explicação. Faz menção à rede que articula o actante ao mencionar o efeito fotoelétrico para sustentar a teoria corpuscular. Nesse caso, percebe-se que, apesar de ser um enunciado tipo 1, existe um elemento que tenta fortalecer a existência do fóton: quem "sugere" é o efeito fotoelétrico (não-humano) e não Albert Einstein (humano). Todos sabemos que o efeito fotoelétrico não executa a ação de sugerir, ao subtrair Einstein do processo de sugestão, entretanto, resguarda-se alguma objetividade ao actante.

Enunciado tipo 2: "Hertz também comprovou para essas ondas as propriedades de reflexão, refração, interferência, difração, polarização e a velocidade de propagação." (Bonjorno et al., 2016, p. 186)

Dictum: As ondas têm a propriedade de reflexão, refração, interferência, difração, polarização e a velocidade de propagação.

Análise do modus: O autor insiste na generalização, ao evidenciar diversos 
fenômenos que são explicados a partir da teoria ondulatória. O verbo comprovar aumenta o grau de facticidade da teoria.

Enunciado tipo 2: "As expressões $\mathrm{E}=\mathrm{hf}$ e $\mathrm{Ec}{ }_{\text {máx }}=\mathrm{hf}-\mathrm{W}$ foram suficientes para explicar o efeito fotoelétrico e reacender a discussão sobre o caráter corpuscular da luz." (Gaspar, 2016, p. 195)

Dictum: A luz é composta por corpúsculos.

Análise do modus: Faz menções à rede da teoria, mostrando equações e fenômenos que a sustentam. O trecho "reacender a discussão" enfraquece a realidade da teoria corpuscular ao denotar tom conjectural. O agente da frase, nesse caso, é não-humano. Ou seja, novamente, apaga-se o papel do agente humano no processo, o que resguarda a objetividade do que está sendo proposto.

Enunciado tipo 3: "Apesar de a natureza ondulatória da luz ser discutida desde o século XVII, somente no início do século XIX o médico e linguista britânico Thomas Young (Figura 6.30) conseguiu demonstrar a interferência das ondas luminosas." (Pietrocola et al., 2016, p. 137)

Dictum: As ondas luminosas interferem.

Análise do modus: O início do modus enfraquece a proposição, ao indicar que durante séculos a teoria não possuía bons argumentos que a sustentassem. No entanto, ao fazer menções à rede da teoria (data aproximada e o nome de um cientista), o modus passa a fortalecer a teoria ondulatória. O agente da frase é humano, Thomas Young.

Enunciado tipo 3: "A teoria desenvolvida por Maxwell levou à conclusão da existência das ondas eletromagnéticas, que seriam constituídas pela combinação de campos elétricos e magnéticos induzidos variáveis que se sustentariam mutuamente." (Bonjorno et al., 2016, p. 185)

Dictum: As ondas eletromagnéticas são constituídas por campos elétricos e magnéticos que se sustentam mutuamente.

Análise do modus: $\mathrm{O}$ autor da teoria é citado (Maxwell). Os tempos verbais dos verbos "ser" e "sustentar" indicam suposição, ou seja, a teoria (agente não-humano) leva a crer que as ondas eletromagnéticas se comportam desta maneira. A estrutura da frase diminui a facticidade do actante. Este enunciado poderia ser catalogado como tipo 2, por generalizar a partir de uma teoria.

Na Figura 10 estão dispostos exemplos de frases referentes a cada tipo de enunciado dos três livros analisados.

Segundo Latour e Woolgar, os tipos mais frequentes de enunciados encontrados em manuais (livros didáticos) seriam os do tipo 4. No entanto, nossa análise não corrobora sua proposição no caso específico da radiação eletromagnética. Além de possuir todos os tipos de enunciados, destaca-se a dificuldade em encaixar alguns deles em apenas uma das cinco categorias latourianas. Comumente frases possuem elementos que se enquadram em ao menos dois tipos de enunciados. Não podemos afirmar nada sobre a trajetória ontológica de outros actantes - o que demandaria outros estudos. 


\begin{tabular}{|c|c|}
\hline $\begin{array}{l}\text { Tipo de } \\
\text { Enunciado }\end{array}$ & Frases retiradas dos livros analisados \\
\hline \multirow[t]{2}{*}{ Tipo $1^{10}$} & $\begin{array}{l}\text { ii) "Finalmente, o efeito fotoelétrico voltava a sugerir que a luz e todas as ondas } \\
\text { eletromagnéticas se comportavam como pacotes de energia, ou seja, como partículas } \\
\text { bem delimitadas se propagando no espaço." (Pietrocola et al., 2016, p. 206) }\end{array}$ \\
\hline & $\begin{array}{l}\text { iii) "O processo mais simples que pode ser imaginado é aquele em que um quantum de } \\
\text { luz transfere toda a sua energia a um único elétron." (Gaspar, 2016, p. 193) }\end{array}$ \\
\hline \multirow{3}{*}{ Tipo 2} & $\begin{array}{l}\text { i) "Hertz também comprovou para essas ondas as propriedades de reflexão, refração, } \\
\text { interferência, difração, polarização e a velocidade de propagação." (Bonjorno et al., } \\
\text { 2016, p. 186) }\end{array}$ \\
\hline & $\begin{array}{l}\text { ii) "Ao longo da história da Ciência descobriu-se que alguns fenômenos só podem ser } \\
\text { compreendidos quando se considera a luz uma onda eletromagnética..." (Pietrocola et } \\
\text { al., 2016, p. 126) }\end{array}$ \\
\hline & $\begin{array}{l}\text { iii) "As expressões } \mathrm{E}=\mathrm{hf} \text { e } \mathrm{Ec} c_{\text {máx }}=\mathrm{hf}-\mathrm{W} \text { foram suficientes para explicar o efeito } \\
\text { fotoelétrico e reacender a discussão sobre o caráter corpuscular da luz." (Gaspar, 2016, } \\
\text { p. 195) }\end{array}$ \\
\hline \multirow{3}{*}{ Tipo 3} & $\begin{array}{l}\text { i) "A teoria desenvolvida por Maxwell levou à conclusão da existência das ondas } \\
\text { eletromagnéticas, que seriam constituídas pela combinação de campos elétricos e } \\
\text { magnéticos induzidos variáveis que se sustentariam mutuamente." (Bonjorno et al., } \\
\text { 2016, p. 185) }\end{array}$ \\
\hline & $\begin{array}{l}\text { ii) "Apesar de a natureza ondulatória da luz ser discutida desde o século XVII, somente } \\
\text { no início do século XIX o médico e linguista britânico Thomas Young (Figura 6.30) } \\
\text { conseguiu demonstrar a interferência das ondas luminosas." (Pietrocola et al., 2016, p. } \\
\text { 137) }\end{array}$ \\
\hline & $\begin{array}{l}\text { iii) "A primeira observação do comportamento individual dos fótons foi feita pelo físico } \\
\text { britânico Geoffrey I. Taylor (1886-1975) por volta de 1910." (Gaspar, 2016, p. 200) }\end{array}$ \\
\hline \multirow{3}{*}{ Tipo 4} & $\begin{array}{l}\text { i) "Os diversos tipos de ondas eletromagnéticas recebem diferentes nomes, que variam } \\
\text { de acordo com seus respectivos intervalos de frequência, comprimento de onda ou a } \\
\text { forma como são produzidas." (Bonjorno et al., 2016, p. 186) }\end{array}$ \\
\hline & $\begin{array}{l}\text { ii) "Ao conjunto de sete tipos de onda eletromagnética dá-se o nome de espectro } \\
\text { eletromagnético..." (Pietrocola et al., 2016, p. 128) }\end{array}$ \\
\hline & $\begin{array}{l}\text { iii) "Sabe-se também que as ondas eletromagnéticas não tem meio de suporte para se } \\
\text { propagarem..." (Gaspar, 2016, p. 189) }\end{array}$ \\
\hline \multirow{3}{*}{ Tipo 5} & $\begin{array}{l}\text { i) "Essas ondas necessitam de estações retransmissoras para serem captadas a longa } \\
\text { distância." (Bonjorno et al., 2016, p. 187) }\end{array}$ \\
\hline & $\begin{array}{l}\text { ii) "Quanto maior a intensidade da luz incidente, mais fótons atingem a superfície do } \\
\text { metal, fazendo um número maior de elétrons ser emitido." (Pietrocola et al., 2016, p. } \\
\text { 204) }\end{array}$ \\
\hline & iii) “Cada fóton passa apenas por uma das fendas de cada vez." (Gaspar, 2016, p. 201) \\
\hline
\end{tabular}

Figura 10. frases retiradas dos livros analisados

Nossa análise identificou recursos discursivos usados pelos autores de livros didáticos na construção das trajetórias ontológicas da luz como onda ou partícula, que

10 Não há enunciados do tipo no livro (Bonjorno et al., 2016). 
não se assemelham aos recursos utilizados no laboratório. Os três primeiros tipos de enunciados estão recheados de agentes não-humanos e de variadas menções à rede. A estrutura das frases e os verbos utilizados nestes enunciados são voltados para transmitir a ideia de uma Ciência em construção. O tom conjectural, por exemplo, deve ser catalogado como enunciado tipo 1 e a menção ao autor da teoria, como tipo 3, no entanto, são encontradas diversas frases com as duas características. Frases com modus que insistem na generalização dos dados (tipo 2) frequentemente estão mescladas com conjecturas (tipo 1) ou menção ao autor (tipo 3). Tal complexidade, reforça a necessidade da arguição fraseológica apresentada na segunda etapa de análise qualitativa, que não somente complementa, como elucida todo o processo de análise.

\section{Conclusões e Implicações}

O presente artigo teve como objetivo analisar a trajetória ontológica de diferentes interpretações da radiação eletromagnética, em livros didáticos aprovados no edital do PNLDEM 2018, de acordo com a tipologia proposta por Bruno Latour em seu livro $A$ vida de laboratório, fazendo parte de uma sequência de trabalhos em que propusemos um dispositivo analítico de textos didáticos de Ciência.

Diversos artigos destinados à análise de livros didáticos concordam em relação à importância destes livros para a Educação em Ciências, por serem uma das únicas fontes de saberes voltados para a escola dos professores da educação básica. A literatura aponta para a necessidade de debates em torno do que seria importante estar presente nestes livros, principalmente em relação a qual visão de Ciência deveria ser abordada ao longo dos textos, a necessidade de explorar a potencialidade de temas ligados ao movimento Ciência, Tecnologia e Sociedade (CTS) e à linguagem utilizada para apresentar tópicos de Física Moderna. Neste sentido, nosso trabalho dialoga com os resultados apresentados nestas pesquisas da área de Educação em Ciências, que apontam para a necessidade da análise do discurso apresentado em livros didáticos e para a revisão da abordagem epistemológica utilizada pelos autores destes livros. Além disso, nosso artigo avança no debate ao propor um novo dispositivo analítico de textos didáticos que pode ser utilizado para o estudo dos demais livros didáticos de Ciências presentes no edital do PNLDEM, assim como manuais de graduação e livros afins. Destacamos que este método pode ser utilizado para avaliar outros temas relacionados à Educação em Ciências, podendo ser hibridizado com outros métodos de análise de livros didáticos.

Não só propomos uma ferramenta de análise como a utilizamos e obtivemos resultados interessantes em relação à maneira como os autores apresentam a natureza da luz. Nossa arguição apresentou que há diferenças nas abordagens dos autores, no entanto, pontos relevantes convergiram para o mesmo resultado. Dentre vários pontos de interseção, três deles devem ser destacados. O primeiro aspecto em comum se refere ao fato de que somente a luz ondulatória é estabilizada e somente no contexto clássico. O segundo fator comum é a presença de enunciados do tipo 4 e/ou 5 (alto grau de realidade) para interpretações ontológicas antagônicas, ou seja, atribui-se realidade à 
interpretação ondulatória e, ao mesmo tempo, à interpretação corpuscular. Portanto há uma incoerência ontológica, pois se afirmamos que a luz é onda, ela não pode ser partícula e vice-versa. O terceiro é a forma independente como são apresentadas as interpretações nos diferentes capítulos/unidades ou seções do livro. Uma interpretação que é autonomizada num capítulo, ou não é mencionada ou é desestabilizada no outro. Considerando os contextos clássico e moderno, ao final do processo, nenhuma versão é estabilizada, mesmo que haja uma grande quantidade de enunciados tipo 4 e 5 para diferentes versões. Concluímos que a trajetória ontológica da luz nos livros analisados não se assemelha à trajetória ontológica de actantes em laboratórios, ou seja, não há um processo de estabilização ontológica para uma única interpretação.

De acordo com Latour a educação em Ciências faz parte de um dos elos da Ciência, a representação pública. Caso este elo, ou qualquer um dos outros seja enfraquecido, o ciclo da Ciência é interrompido. Desta forma a educação básica e a Ciência são interdependentes. Por isso estendemos os estudos científicos de Latour para analisar a Educação em Ciências.

Entendemos que o ensino de Física Quântica deve ser estruturado de forma a explorar suas diversas potencialidades. Para tanto, faz-se necessário renunciar a discussões meramente instrumentais da FQ e aprofundar o debate em torno de questões filosóficas e epistemológicas.

Nesse trabalho, apresentamos diferentes tipos de interpretações possíveis para a natureza ontológica da radiação eletromagnética. Um possível caminho para ensinar tal tema seria a produção de material didático condizente com um contexto plural de interpretações e com uma abordagem pedagógica que fomentasse a discussão sobre tal pluralidade. Nessa abordagem, não seria desejável atribuir alto grau de realidade para diferentes interpretações sem uma discussão mais profunda sobre o problema ontológico, explicitando as potencialidades e as limitações de cada uma das possibilidades. A Educação em Ciências, de acordo com os Estudos das Ciências, pode evidenciar aos estudantes outras questões relacionadas à natureza da Ciência que historicamente não são trabalhadas na educação básica, abrindo a caixa preta da Ciência. Tal modificação na abordagem de ensino vai ao encontro de recomendações existentes na literatura da área, que aponta para a necessidade da introdução de visões sobre a natureza da Ciência com base em teorias epistemológicas contemporâneas.

Por fim destacamos que a dificuldade em classificar os enunciados de acordo com a tipologia de Latour reforça a necessidade de avanços teóricos na aproximação entre os Estudos sociológicos das Ciências e a análise do discurso. No entanto, mesmo com as limitações relatadas, nossa ferramenta demonstrou grande potencial de análise para a Educação em Ciências. O livro didático faz parte da cultura escolar e se mostra fundamental não somente para a compreensão dos conhecimentos científicos, mas também para o desenvolvimento da visão dos estudantes sobre a natureza da Ciência. 


\section{Referências}

Badino, M., \& Navarro, J. (2013). A History of Quantum Physics through Textbooks. Berlin: Max Planck Research Library for the History and Development of Knowledge.

Ballentine, L. E. (1970). The Statistical Interpretation of Quantum Mechanics. Rev. Mod. Phys., 42(4), 358-381. https://doi.org/10.1103/RevModPhys.42.358

Bohr, N. (1928). The Quantum Postulate and the Recent Development of Atomic Theory. Nature, 121, 580-590.

Bonjorno, J., Ramos, C., Prado, E., Bonjorno, V., Bonjorno, M., Casemiro, R., \& Bonjorno, R. (2016). Física: eletromagnetismo, física moderna. (FTD, Ed.) (3a ed.). São Paulo.

Callon, M. (1984). Some elements of a sociology of translation: domestication of the scallops and the fishermen of St Brieuc Bay. The Sociological Review, 32, 196-233. https:// doi.org/10.1111/j.1467-954X.1984.tb00113.x

Cassab, M., \& Martins, I. (2008). Significações de professores de Ciências a respeito do livro didático. Ensaio Pesquisa Em Educação Em Ciências, 10(1), 1-24.

Collins, H. M., \& Evans, R. (2002). The third wave of science studies: Studies of expertise and experience. Social Studies of Science, 32(2), 235-296. https://doi. org/10.1177/0306312702032002003

Compton, A. H. (1923). A Quantum Theory of the Scattering of X-rays by Light Elements. Physical Review, 21(5), 483-502. https://doi.org/10.1103/PhysRev.21.483

Contents, T. H. E., Modern, O. F., In, P., Books, E., Physics, O. F., \& High, O. F. (2019). Os conteúdos de física moderna em livros didáticos de física do Educational books of physics of high. Debates em Educação, 11, 106-124. https://doi.org/10.28998/21756600.2019v11n24p106-124

De Broglie, L. (1922). Rayonnement noir et quanta de lumière. Journal Physical Radium, 3(11), 422-428.

De Broglie, L. (1924). A tentative theory of light quanta. Philosophical Magazine, 47(278), 446-458.

Dirac, P. A. M. (1958). The Principles of quantum mechanics. Claredon Press.

Einstein, Alber. (1905). Über einen die Erzeugung und Verwandlung des Lichtes betreffenden heuristischen Gesichtspunkt. Annalen de Phisik, 17(132).

Einstein, Albert. (1909). On the Development of Our Views Concerning the nature and constitutio of radiation. In Albert Einsteins - The Swiss Years: Writings, 1900-1909 (English translation supplement).

Feynman, R., Leighton, R., \& Sands, M. (2013). Feynman's Lectures on Physics. California Institute of Technology. 
FNDE, 2017. (n.d.). Portal do FNDE. https://www.fnde.gov.br/component/k2/ item/514? Itemid=890

Gaspar, A. (2016). Compreendendo a física: eletromagnetismo e física moderna (3a Ed.). Ática.

Geertz, C. (1973). The interpretation of Cultures. Basic Book.

Grangier, P., Roger, G., \& Aspect, A. (1986). Experimental Evidence for a Photon Anticorrelation Effect on a Beam Splitter: A New Light on Single-Photon Interferences. Europhysics Letters (EPL), 1(4), 173-179. https://doi.org/10.1209/0295-5075/1/4/004

Greenstein, G., \& Zajone, A. G. (2006). The Quantum Challenge - Modern Research on the Foundation of Quantum Mechanics. Jones and Bartlett Publishers.

Greimas, A. J., \& Courtés, J. (1982). Semiotics and Language. Indiana University Press.

Jammer, M. (1974). The Philosophy of Quantum Phyiscs. John Wiley and Sons.

Justi, R., \& Gilbert, J. (2000). History and philosophy of science through models: some challenges in the case of "the atom." International Journal of Science Education, 22(9), 993-1009. https://doi.org/10.1080/095006900416875

Kaiser, D. (2005). Drawing Theories Apart: The dispersion of Feynmann's diagrams in Postwar Physics. Chicago University Press.

Kaiser, D. (2006). Pedagogy and the practice of science. Cambridge: The MIT Press. https://doi.org/Doi 10.1080/14697680601043290

Kopp, F. A., \& Almeida, V. de. (2019). Analogias e metáforas no ensino de Física Moderna apresentadas nos livros didáticos aprovados pelo PNLD 2018. Caderno Brasileiro de Ensino de Física, 36(1), 69-98.

Kuhn, T. (1978). Black-Body Theory and the Quantum Discontinuity, 1894-1912. Oxford University Press.

Kuhn, T. (1996). The structure of Scientific Revolutions (3 Ed). The University of Chicago Press.

Latour, B. (1993). The Pasteurization of France. Harvard University Press.

Latour, B. (1994). Jamais fomos modernos. 1 Ed. Editora 34.

Latour, B. (1999). Pandora's Hope: Essays on the reality of Science Studies. Harvard University Press.

Latour, B. (2005). Reassembling the Social: An Introduction to Actor Network Theory. Oxford University Press.

Latour, B., \& Woolgar, S. (1986). Laboratory Life: The construction of scientific facts. Princeton University Press. 
Law, J. (1984). On the methods of long-distance control: Vessels, navigation and the Portuguese route to India. Sociological Review, 32(S1), 234-263. https://doi.org/10.1111/ j.1467-954X.1984.tb00114.x

Lightman, B. (2016). A Companion to the History of Science. John Willey and Sons.

Lima, N. W., Ostermann, F., \& Cavalcanti, C. J. de H. (2017). Física Quântica no ensino médio: Uma análise bakhtiniana de enunciados em livros didáticos de Física aprovados no PNLDEM 2015. Caderno Brasileiro de Ensino de Física, 435-459.

Lima, N. W., Ostermann, F., \& Cavalcanti, C. J. de H. (2018a). A não-modernidade de Bruno Latour e suas implicações para a Educação em Ciências. Caderno Brasileiro de Ensino de Física, 34(2), 367-388. https://doi.org/10.5007/2175-7941.2018v35n2p367

Lima, N. W., Souza, B. B. De, Cavalcanti, C. J. de H., \& Ostermann, F. (2018b). Um Estudo Metalinguístico sobre as Interpretações do Fóton nos Livros Didáticos de Física Aprovados no PNLDEM 2015: Elementos para uma Sociologia Simétrica da Educação em Ciências. Revista Brasileira de Pesquisa Em Educação Em Ciências, 18(1), 331-364. https://doi.org/10.28976/1984-2686rbpec2018181331

Lima, N. W., Vazata, P. A. V., Ostermann, F., Cavalcanti, C. J. de H., \& Moraes, A. G. (2019). Educação em Ciências nos Tempos de Pós-Verdade: Reflexões Metafísicas a partir dos Estudos das Ciências de Bruno Latour. Revista Brasileira de Pesquisa Em Educação Em Ciências, 19, 155-189. https://doi.org/10.28976/1984-2686rbpec2019u155189

Marques, T. C. de F., Martins, T. C., Novais, A. D. L. F., Gomes, L. M., Paschoal, C. M. M., Fernandes, C. S., \& Ferreira, F. C. L. (2019). Ensino de física moderna e contemporânea na última década: Revisão sistemática de literatura. Scientia Plena, 15(7), 1-8. https:// doi.org/10.14808/sci.plena.2019.074809

Martins, I. (2006). Analisando livros didáticos na perspectiva dos Estudos do Discurso: compartilhando reflexões e sugerindo uma agenda para a pesquisa. Pro-Posições, 1(49), $117-136$.

Martins, R. de A., \& Rosa, P. S. (2014). História da teoria quântica - a dualidade ondapartícula, de Einstein a De Broglie. Livraria da Física.

Montenegro, R. L., \& Pessoa Jr., O. (2002). Interpretações da teoria quântica e as concepções dos alunos do curso de física. Investigações Em Ensino de Ciências, 7(2), $107-126$.

Pessoa Jr., O. (2003). Conceitos de Física Quântica. Livraria da Física.

Pietrocola, M., Pogibin, A., Andrade, R., \& Romero, T. R. (2016). Física em contextos, 3. (1a ed.). E. do Brasil.

Popper, K. (2002). The Logic of Scientific Discovery. Routledge.

Sartre, J.-P. (2007). Existentialism is a Humanism. Yale University Press. 
Schrodinger, I. (1928). Collected Papers on Wave Mechanics. Backie \& Son Limited.

Vazata, P. A. V., Lima, N. W., Ostermann, F., \& Cavalcanti, C. J. de H. (2018). Proposta de um dispositivo analítico para avaliação da estabilização ontológica de um actante em livros didáticos à luz dos estudos da ciência de Bruno Latour. In Snef XXIII.

Vazata, P. A. V., Lima, N. W., Ostermann, F., \& Cavalcanti, C. J. de H. (2019). A Natureza da Luz no Contexto Clássico e Moderno: Uma análise de enunciados de um Livro de Física aprovado no PNLDEM 2018 a partir dos Estudos da Ciência de Bruno Latour. XII O Encontro Nacional de Pesquisa em Educação em Ciências - ENPEC. ABRAPEC.

Weinstein, M. (2008). Finding Science in the school body: Reflections on transgressing the boundaries of science education and the social studies of science. Science Education, 92(3), 389-403.

Zang, C., Giacosa, N., \& Chrobak, R. (2019). El contenido científico en libros de textos: una revisión en revistas de acceso libre. Latin-American Journal of Physics Education, 13, $1-23$. 


\section{Pedro Antônio Viana Vazata}

https://orcid.org/0000-0001-8780-5343

Universidade Federal do Rio Grande do Sul Programa de Pós-Graduação em Ensino de Física Instituto de Física Porto Alegre, Rio Grande do Sul Brasil profpedrovazata@gmail.com

\section{Nathan Willig Lima}

http://orcid.org/0000-0002-0566-3968 Universidade Federal do Rio Grande do Sul Porto Alegre, Brasil nathan.lima@ufrgs.br

\section{Fernanda Ostermann}

https://orcid.org/0000-0002-0594-2174 Universidade Federal do Rio Grande do Sul

Porto Alegre, Brasil fernanda.ostermann@ufrgs.br

Cláudio José de Holanda Cavalcanti

https://orcid.org/0000-0002-2477-3150 Universidade Federal do Rio Grande do Sul Porto Alegre, Brasil claudio.cavalcanti@ufrgs.br

Submetido em 18 de março de 2020 Aceito em 22 de junho de 2020 Publicado em 28 de agosto de 2020 